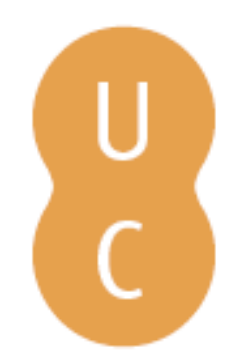

\title{
nommalina
}

\section{O impacto das alterações das rotinas produtivas e do advento da internet na relação entre fontes e jornalistas: estudo exploratório sobre o tratamento noticioso de protestos sociais}

\author{
Autor(es): Miranda, João \\ Publicado por: Imprensa da Universidade de Coimbra \\ URL \\ persistente: URI:http://hdl.handle.net/10316.2/41775 \\ DOI: $\quad$ DOl:https://doi.org/10.14195/978-989-26-1362-8_2
}

Accessed : $\quad$ 26-Apr-2023 14:37:07

A navegação consulta e descarregamento dos títulos inseridos nas Bibliotecas Digitais UC Digitalis, UC Pombalina e UC Impactum, pressupõem a aceitação plena e sem reservas dos Termos e Condições de Uso destas Bibliotecas Digitais, disponíveis em https://digitalis.uc.pt/pt-pt/termos.

Conforme exposto nos referidos Termos e Condições de Uso, o descarregamento de títulos de acesso restrito requer uma licença válida de autorização devendo o utilizador aceder ao(s) documento(s) a partir de um endereço de IP da instituição detentora da supramencionada licença.

Ao utilizador é apenas permitido o descarregamento para uso pessoal, pelo que o emprego do(s) título(s) descarregado(s) para outro fim, designadamente comercial, carece de autorização do respetivo autor ou editor da obra.

Na medida em que todas as obras da UC Digitalis se encontram protegidas pelo Código do Direito de Autor e Direitos Conexos e demais legislação aplicável, toda a cópia, parcial ou total, deste documento, nos casos em que é legalmente admitida, deverá conter ou fazer-se acompanhar por este aviso.

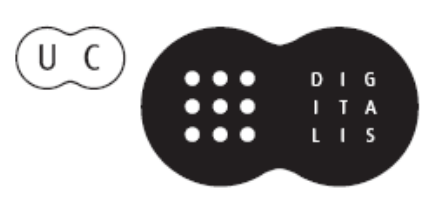




\section{PESSOAS E IDEIAS EM TRÂNSITO}

Percursos e Imaginários

RITA BASÍLIO DE SIMÕES

CLARA SERRANO

SÉRGIO NETO

JOÃO MIRANDA

(ORGS.)

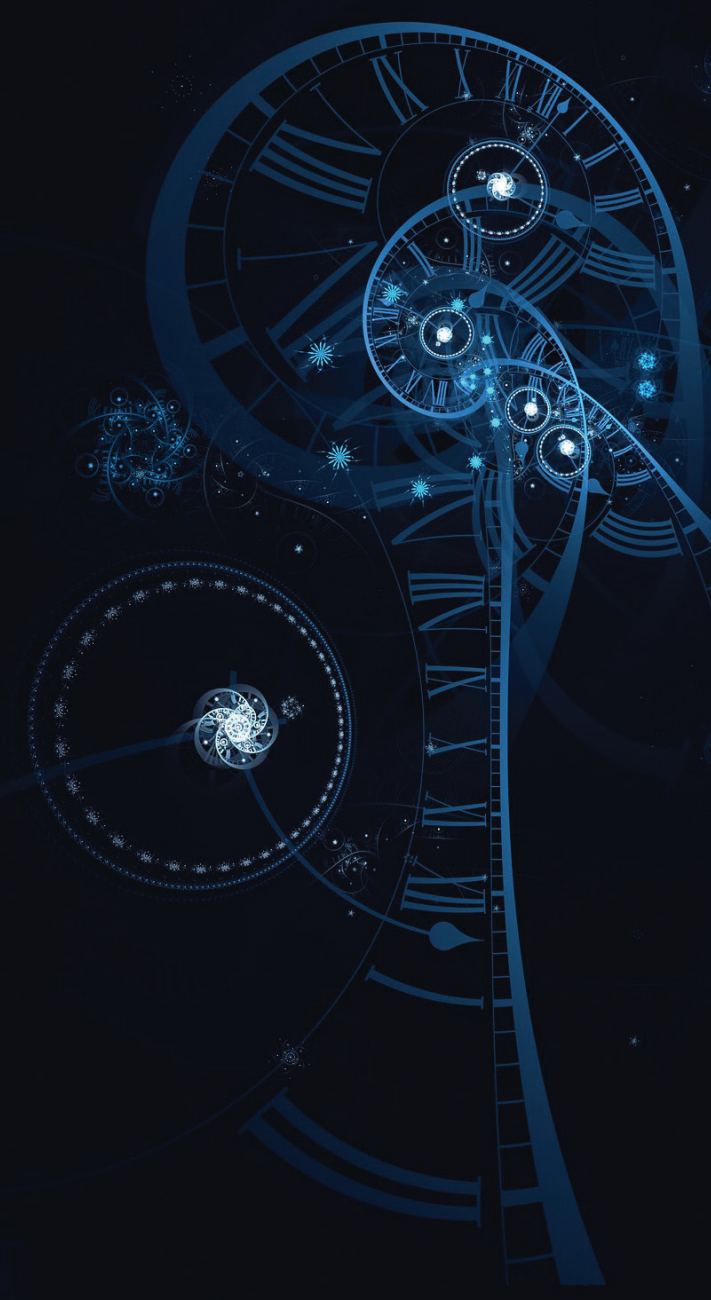

IMPRENSA DA

UNIVERSIDADE

DE COIMBRA

COIMBRA

UNIVERSITY

PRESS 
O IMPACTO DAS ALTERAÇÕES DAS ROTINAS PRODUTIVAS E DO ADVENTO DA INTERNET NA RELAÇÃO ENTRE FONTES E JORNALISTAS: ESTUDO EXPLORATÓRIO SOBRE O TRATAMENTO NOTICIOSO DE PROTESTOS SOCIAIS

João Miranda

CEIS20/FLUC 0000-0002-4720-3724

Resumo: A mutação das rotinas produtivas do jornalismo e o progresso tecnológico dos canais de comunicação vieram reformatar os modelos de relação entre jornalistas e fontes de informação. A partir desta hipótese, este texto reúne diferentes propostas teóricas sobre a problemática da correspondência entre repórteres e as suas fontes. Uma análise transversal a artigos sobre manifestações demonstra um recurso relevante a fontes não identificadas, a não revelação do método de contacto com as fontes e um uso significativo de redes sociais como fonte.

Palavras-chave: Fontes; Rotinas produtivas; Gatekeeping; Redes sociais.

Abstract: The mutation of the productive routines of journalism and the technological progress of the communication 
channels reshaped the models of relationship between journalists and their sources. Starting from this hypothesis, this paper brings together different theoretical propositions on the subject of reporters and sources relationship. A cross analysis of newspaper articles on political demonstrations shows a trend use of unidentified sources.

Keywords: Journalism sources; Productive routines; Gatekeeping; Social networks. 


\section{Introdução}

O processo de produção de uma notícia é, em si mesmo, um ato de construção social da realidade (Tuchman, 1978), isto é, a noção de um exercício de criação de um ideário partilhado, mas ao mesmo tempo a ideia de que depende intimamente de fatores externos ao jornalista, à redação e ao próprio jornalismo. Este exercício resulta, portanto, de uma relação de influências de âmbito pessoal, social e cultural, onde as práticas e normas definidas ou ideadas encerram uma função fulcral na garantia da qualidade do produto jornalístico (Sousa, 2000). A relação com a fonte da notícia, e o seu desenvolvimento dentro das rotinas produtivas, assume um papel essencial neste processo construtivo (Sigal, 1973).

A mutação do paradigma socioprofissional do jornalismo, e sobretudo dos modelos laborais em que ele se desenvolve, e o progresso tecnológico têm contribuído em grande medida para uma alteração das rotinas produtivas (Sousa, 2000; Ramonet, 1999) e, consequentemente, das relações entre jornalistas e fontes. A compreensão desta perspetiva torna-se tão mais premente quando estas práticas se observam no âmbito do jornalismo político, onde o combate pelo domínio da definição do agendamento está mais patente (Muñoz-Alonso e Rospir, 1995).

Considerando tudo isto, este estudo debruça-se sobre o impacto que a alteração das rotinas produtivas resultantes da entrada de novas tecnologias nas redações e o advento da internet produzem sobre a relação das fontes com os jornalistas e de que forma estas lógicas se encontram patentes no jornalismo político. Através de uma análise ao espaço noticioso sobre manifestações nacionais de contestação política, procura perceber-se o contexto das fontes que ocupam o jornalismo político, como é desenvolvida essa relação e que valores conduzem a formulação destes produtos noticiosos. 


\section{Relação entre jornalistas e fontes}

Recuperando a ideia de Leon Sigal (1973), a construção do produto noticioso depende intimamente, numa primeira análise, das fontes consultadas e, posteriormente, das informações por elas prestadas. Daqui resulta óbvia a constatação de Jorge Pedro Sousa (2002), quando reconhece que, perante o poder que assumem na formulação dos conteúdos noticiosos e consequentemente na edificação do espaço público, a problemática do estudo das fontes tenha assumido uma posição central na investigação do campo mediático. Aqui, mais do que encontrar uma definição linear de fontes $^{1}$, ressalva-se a necessidade de compreender as complexas relações entre fontes e jornalistas na produção dos produtos informativos - a dança de procura mútua que Gans (1979) descreve.

Este processo binário (McQuail, 2003) encontra significado na relação persistente entre a busca de informações, por parte dos jornalistas, e a procura de enquadrar as notícias, pelo lado das fontes. É sobretudo a partir desta segunda premissa que Molotch e Lester (1974) definem o conceito de "promotor de notícias", isto é, o exercício voluntário ou involuntário que as fontes desenvolvem no sentido de efetivar certos casos como informação e evitar a notícia de outros. Este processo, continuam os autores, ocorre através da adequação das suas às rotinas produtivas do jornalismo. Como refere Rogério Santos (1997: 76), “o jornalista raramente está em posição de observar o acontecimento - ele precisa de alguém que lhe faça um relato o mais correto possível, que é a fonte”. Assim, resulta claro que, durante o processo de seleção e escrita da notícia - rotinas produtivas -, os jornalistas, conscientemente ou não, sejam influenciados pela perspetiva da fonte (Chaparro, 2001).

\footnotetext{
1 Não obstante encontrarem-se exercícios de concetualização nos trabalhos de Manning (2001), Berlo (2003) ou Santos (2003).
} 
Embora subsista uma proliferação de concetualizações de tipologia de fontes, destaca-se neste estudo o sistema de Ericsson e Chan (1989), que categorizam as fontes entre porta-vozes de organizações governamentais, porta-vozes de organizações não-governamentais, cidadãos individuais e jornalistas. É este primeiro grupo - as fontes oficiais - que Sigal (1973) assume usufruírem de um acesso privilegiado ao espaço informativo e às rotinas de produção mediáticas, menorizando as fontes menos conhecidas. Molotch e Lester (1974) vão mais longe nesta análise, definindo as fontes mais poderosas como capazes de, mais do que se adequarem aos processos de construção informativa, readequarem as próprias rotinas de produção. Stuart Hall (1999) prossegue esta ideia, negando o poder negocial dos jornalistas na sua relação com as fontes. Neste modelo hierárquico, as fontes poderosas - onde se incluem políticos, representantes institucionais, patronato ou dirigentes sindicais - serão capazes de condicionar todo o processo de produção informativo e adequar os enquadramentos aos seus interesses - são assim denominados como "definidores primários" (1999: 253).

Ainda que Molotch e Lester admitam no seu modelo de relação jornalista/fonte uma relativa autonomia dos profissionais nas suas rotinas - sobretudo no que definem ser eventos de "acesso direto" (1974: 109), isto é, construções noticiosas que dependem da flexibilidade e proatividade do jornalista em recolher as informações -, Hall admite que a interpretação primária introduzida pelas fontes poderosas delimita à partida todo o futuro desenvolvimento da produção noticiosa em torno do enquadramento apresentado. Reside, assim, nesta perspetiva elementar do entendimento da relação de domínio da agenda por parte das fontes, a principal crítica apontada por Rogério Santos (1997) à tese de Hall, que a considera truncada da profusão de todo o processo de relações na produção noticiosa, bem como contextual no tempo.

Importa, portanto, recuperar a discussão de Herbert Gans (1979), que centra a sua análise particularmente no processo do newsmaking. 
Esta ideia de inclusão do jornalista no processo encontra-se, de resto, bem patente na concetualização que cria de fonte, isto é, "atores que o jornalista observa ou entrevista" (1979: 80) - aceção que inclui as personagens que contribuem para a construção da narrativa noticiosa através do discurso citado, mas que pode também abranger aqueles que contribuem indiretamente através da sugestão de ângulos ou histórias, porém, figuras que interagem neste processo, enquanto membros de grupos de interesses organizados.

Tal como os restantes autores supracitados, também Gans (1979) realiza uma distinção entre os diversos tipos de fonte - institucionais e oficiosas; estáveis e provisórias; conhecidas e desconhecidas; ativas e passivas. Contudo, o grande contributo do investigador para a presente análise estabelece-se na compreensão que realiza do processo relacional entre fontes e jornalistas como um sistema, onde inclui também as audiências como ator.

Diante desta diversidade complexa de fontes, o jornalista realiza a sua escolha não só baseado no papel e estatuto que ela assume na estrutura social, mas também, introduz Gans (1979), em função das necessidades produtivas.

Segundo esta proposta, Gans (1979) não diverge de Sigal (1973) quando delineia que o acesso das fontes aos media não depende exclusivamente da posição hierárquica ou do papel social que assumem, mas obedece também à facilidade que introduzem no âmbito do processo individual da criação das notícias. Importa, porém, uma distinção, interessante no âmbito deste estudo, entre a relação entre fontes e jornalistas especializados e jornalistas não especializados. Os jornalistas especializados, devido ao âmbito das suas rotinas de trabalho, criam relações contíguas e permanentes com as suas fontes. A partir desta relação de obrigações recíprocas, as fontes acabam por se estabelecer como informadores pessoais e privilegiados dos repórteres, conferindo informações mais completas, muitas vezes do âmbito da confidencialidade. Ao 
mesmo tempo, os jornalistas especializados, integrados na natureza da temática, conseguem ultrapassar a ignorância inerente à multiplicação de questões específicas.

Por seu lado, os jornalistas não especializados lidam na órbita das suas rotinas com acontecimentos e temáticas profusamente díspares entre si. Desenvolvem geralmente este trabalho sem o conhecimento específico das temáticas que reportam, a que se acresce, compreende Gans (1979), a falta diária de tempo. Assim, estes jornalistas acabam por se virar para as fontes autorizadas, a quem reconhecem o cunho de autoridade, mas também de produtividade. No sentido de obliterar alguma incerteza sobre o trabalho produzido, reconhece o autor, estes repórteres operam com outros jornalistas, numa rede de troca de impressões e informações. Isto resulta numa postura passiva dos órgãos de comunicação, que acabam de certa forma permeáveis às fontes que mais prontamente respondem às necessidades dos jornalistas.

Posto se admita a existência de uma série de outras perspetivas sobre esta temática - onde se destacam as propostas de Hess (1984) sobre uma conexão de reação, a ideia da relação de interesse mútuo de Blumler e Gurevitch (1992), ou a questão das pressões levantada por Curran (1977) -, considera-se que os conceitos acima apresentados assumem a capacidade de exprimir o processo relacional entre jornalistas e fontes e a sua hierarquização. Não obstante considerar-se-ão também como referência as questões profissionais do jornalismo colocadas por Elliot e Schlesinger (Apud Santos, 1997) sobre a rotinização e cronometalidade da produção noticiosa (que serão desenvolvidas mais à frente).

\section{Mutação das rotinas produtivas}

Os jornalistas - excetuando o caso dos freelancers -, independentemente do regime laboral adotado, operam em organizações 
onde se releva uma conjugação de um nível intermédio entre a ação pessoal e a ação organizacional. Modelos estruturais onde o trabalho, embora possa decorrer de uma série de fatores de sociabilização, como a imitação, aspirações ou expectativas, depende sobretudo da relação institucional estabelecida dentro da redação. Assim, é esta estrutura e dimensão burocrática que, em última análise, influem no processo da produção noticiosa (Sousa, 2000).

Ainda que este exercício dos jornalistas possa depender substancialmente desta estrutura coletiva, os profissionais possuem hábitos próprios, afetos a processos convencionais e sociais de trabalho: as rotinas de produção. Refere Traquina (1988) que é este exercício de produção que garante ao jornalista a efetivação do seu trabalho ao mesmo tempo que assegura o controlo sobre a qualidade do produto, contra as limitações da pressão de tempo.

Philip Schlesinger (1999) carateriza o produto noticioso como uma mercadoria singular numa perspetiva temporal, da qual o valor de utilização rapidamente se esgota. É, de resto, este atributo que está na origem do pensamento cronométrico que se desdobra entre dois fatores distintos: o imediatismo e a efemeridade da informação, e a imposição da cadência do acontecimento. Embora considere que se encontra já enraizada no ideário dos jornalistas, Schlesinger admite que esta ideologia depende sobretudo das condições do mercado e dos imperativos empresariais - portanto, a concorrência -, que ditam os valores da atualidade e rapidez associados à produção noticiosa.

Ainda sobre a questão dos processos produtivos do jornalismo, Mauro Wolf (2003) explica mesmo que, num sistema de produção de notícias em série, estas rotinas desenvolvem um importante papel no processo informativo e incidem resolutamente nas práticas éticas e deontológicas, bem como na "qualidade da informação". Admite-se, portanto, que este conjunto de operações, que pretendem garantir a prossecução dos valores da responsabilidade social 
do jornalista, pode passar por práticas tão banais como o contacto direto, procura da diversidade das fontes ou a visita ao local em reportagem, logo, o aprofundamento das matérias.

Tuchman (1972) destaca o papel das rotinas produtivas como garantia, mais do que da noção de controlo já aqui desenvolvida, da estruturação e formalização dos procedimentos profissionais do jornalismo e, consequentemente, de mecanismos de defesa relativamente ao seu trabalho. Contudo, Kovach e Rosenstiel (2001) evocam esta mesma condição como um fator negativo. Para os autores este problema ocorre quando as rotinas se vertem numa homogeneização de consciências dentro da redação, em que uma inércia de índole burocrática impõe o seguimento de convenções padronizadas para toda a organização. Esta problemática acentua-se tanto mais quanto se imponha o fluxo de informação e a urgência do fator-tempo.

Contrariedade semelhante é definida por Traquina (1988), quando identifica que a profissão tende a desenvolver-se como um ofício burocratizado, consequência do aumento constante dos fluxos de informação, redução do número de profissionais na redação e, subsequentemente, do aumento da pressão do tempo. Isto resulta no estabelecimento de canais rotineiros onde dominam as fontes acessíveis e de maior facilidade de acesso, o que conduz ao declínio do jornalismo de investigação e aprofundamento, facilitando a manipulação (Sousa, 2000). Ao mesmo tempo, verifica-se uma uniformização do trabalho de gatekeeping, o que acarreta por si uma estandardização dos produtos informativos e uma padronização do pensamento e das ideias veiculadas.

Fruto dos processos de desprofissionalização e proletarização do ofício jornalístico, Ignacio Ramonet (1999) não coloca dúvidas em comparar os repórteres a operários inseridos num modo de produção 'taylorista', onde a sua função é cada vez mais reduzida a agregador de informações, que trata não sob uma lógica que evidencie os juízos da verdade e validade, mas que salienta as questões da profusão 
e da instantaneidade do produto. Resumindo, os novos jornalistas abandonam a sua identidade romântica, para assumir uma nova figura de "retocadores de despachos de agência" (Ramonet, 1999: 51).

A introdução a estes novos contextos laborais da informação encontra-se, de resto, bem precisa no modelo desenvolvido por Erik Neveu (2001) de "jornalismo sentado". Neveu desenvolve a ideia de um jornalismo burocratizado, onde - em contraponto com um repórter em pé, que abandona a redação para contactar com o local do acontecimento e comunicar diretamente com as fontes -, o jornalista assume funções de recolha e tratamento de declarações de fontes acessíveis ou, até mesmo, de outros produtos noticiosos.

Ainda sobre esta questão, interessará rever a análise de Fábio Henrique Pereira (2003) ao desenvolvimento das rotinas produtivas do sítio noticioso "Correio WEb", onde desvenda caraterísticas pertinentes sobre a lógica de envio de repórteres para a rua, tais como a eleição da permanência na redação relativamente ao abandono do local do trabalho - esta prática só ocorre quando não existem informações passíveis de serem cobertas a partir da redação - ou a preferência sobre a cobertura extensiva e massificada de um acontecimento, a partir de outros meios, relativamente ao envio do jornalista.

Aqui, torna-se também interessante recuperar o inquérito realizado entre os jornalistas da área de Lisboa, onde 59,9\% dos jornalistas admitiam ter as assessorias de imprensa e os gabinetes de relações públicas como principais fontes (Serrano, 1998).

Finalmente, um outro estudo (Miranda, 2012), desenvolvido a partir de um inquérito realizado entre jornalistas dos principais diários portugueses e dos jornais com maior tiragem na região de Coimbra, indicava que apenas $8,1 \%$ dos profissionais inquiridos admitia contactar "sempre" diretamente com as fontes, contrastando com 44,6\% que concordava realizá-lo "muitas vezes", 37,8\% que respondia realizá-lo "frequentemente", ou mesmo 9,5\% que admitia " raramente" desenvolver um contacto direto com as fontes. 
Já quando sondados sobre a quantidade de vezes a que recorrem somente a comunicados ou a notas de imprensa como única fonte, $50 \%$ dos respondentes explicou praticá-lo raramente, $26,3 \%$ frequentemente, $17,1 \%$ nunca e $6,6 \%$ admitia realizá-lo "muitas vezes". No mesmo sentido, sobre o contacto direto com o local do acontecimento, $35,5 \%$ dos inquiridos abandona frequentemente a redação em reportagem, 30,3\% mencionou efetuá-lo "muitas vezes", 28,9\% raramente e 5,3\% nunca o faz (Miranda, 2012).

Estes últimos dados, embora não corroborem a ideia de uma mutação das rotinas completa para o paradigma desenvolvido por Erik Neveu, interessam para o âmbito deste estudo quando se denota, através de uma correlação entre estas problemáticas e a variável da editoria em que os jornalistas desenvolvem o seu trabalho, que é nas secções tradicionalmente afetas ao objeto de estudo que aqui se desenvolve que os preceitos do cânone do "jornalismo sentado" se encontram mais enraizados - Sociedade, País/Portugal e Economia (Miranda, 2012).

É, contudo, possível articular uma conexão destes resultados com o que já se desenvolveu ser um crescimento do ritmo de produção do jornalismo, quando se verifica o volume de matéria produzida: apenas $8,1 \%$ dos inquiridos aponta redigir, em média, um artigo por edição. O grupo de jornalistas que redige dois a três artigos por edição é o que assume maior peso, em 45,9\% da amostra, seguindo-se os jornalistas que escrevem entre seis e dez artigos por edição (21,6\%), os que escrevem entre quatro e cinco (17,6\%) e, finalmente, os que referem redigir onze ou mais artigos por edição, com $6,8 \%$.

\section{O advento da internet e o declínio do gatekeeping}

Não obstante os diversos fatores que operam nesta mutação contínua dos processos de produção jornalística - onde se podem 
inscrever agentes de âmbito económico, profissional ou tecnológicos -, o desenvolvimento de novos canais digitais de comunicação e o advento da internet agem resolutamente na formulação de uma nova ideologia profissional ajustada a responder à exigência do imediatismo da informação (Meireles, 2007). Como resume John Pavlik (2005: 138), "a internet oferece um acesso instantâneo a imensas bases de dados, aos quais antes só se poderia aceder examinando-os in situ". Também Ross e Middleberg (Apud Gomes, 2009) evidenciam o potencial da internet na facilitação do trabalho jornalístico, no contacto com as fontes e na receção de comunicados de imprensa.

Este movimento dos jornalistas para a rede, enquanto fonte de informação (Bastos, 2002), fica ainda bem explícito no estudo desenvolvido por Rui Miguel Gomes (2009), onde a maioria dos jornalistas inquiridos admite os benefícios resultantes do advento da internet como proveniência de informação, e onde, uma margem relevante - para este caso, dos repórteres das áreas de Economia e Sociedade - entende que a internet substitui as fórmulas tradicionais de contacto com as fontes.

Enquanto o e-mail ficou já bem patente como um instrumento de trabalho indispensável, não só na comunicação com as fontes, mas também como recetor de comunicados e notas de imprensa (Gomes, 2009), a proliferação das redes sociais - onde se incluem, a título de exemplo, os blogues, o Facebook ou Twitter - veio gerar um novo paradigma, em que se assiste a uma multiplicação de emissores e em que os utilizadores passam a constituir-se fontes (Machado, 2013). Raquel Recuero (2009) - que distribui a redefinição que as redes sociais introduziram nas práticas jornalísticas em três funções distintas: as redes sociais como fontes produtoras de informação, como filtros de informação e como espaços de reverberação dessas informações - identifica que este movimento ocorre com origem na diversidade de fontes mas, sobretudo, na 
novidade e na prontidão da informação que estes novos espaços online possibilitam. Neste sentido, as movimentações nestes fóruns acabam por se transformar por si em fontes de informação, tendência crescente comprovada por vários indicadores (Mitchell \& Rosenstiel, 2012; Oriella PR Network, 2011).

Este novo padrão foi rapidamente apreendido pelas fontes e promotores de notícias - aqui entendidos segundo a tipologia de Molotch e Lester (1974) -, que começaram a ocupar estes espaços com informações em primeira mão (Canavilhas, 2010). As redes sociais assumiram uma expressão tal como meio de divulgação de informação, que a própria comunicação política redefiniu paradigmaticamente os seus canais de mensagem, multiplicando-se os fenómenos de anúncios e comunicações de figuras políticas que privilegiam a comunicação através do Facebook ou do Twitter relativamente aos canais tradicionais de comunicação (Canavilhas, 2009; Antunes, 2012). Ao mesmo tempo, esta possibilidade de interação aberta veio criar novos canais de discussão e aumentar as possibilidades de gerar a exteriorização de discussões até então circunscritas a grupos fechados, que não tinha acesso aos meios de comunicação. Em suma, o extrapolar da ideia de democratização gerada pelos novos espaços digitais (Castells, 2009) ${ }^{2}$. Conscientes desta nova realidade e das possibilidades inerentes, multiplicaram-se os diferentes grupos de ação que começaram a fazer uso destas ferramentas de comunicação (Recuero, 2009). Embora não subsista aqui uma completa inversão lógica das proposições de poder no acesso das fontes à comunicação propostas pelos autores aqui analisados, verifica-se uma transformação na tipologia assente num modelo hierárquico. De facto, fica patente

2 Ainda que se encontre na proposta teórica do "capitalismo comunicativo", de Jodi Dean (2009), uma explicação construtiva para a realidade destas mensagens serem incapazes de penetrar todas as esferas do domínio público. 
uma adequação destas novas fontes às premissas de Molotch e Lester (1974), sobre a adaptação mútua às rotinas de produção, bem como resulta explícita uma correspondência com as proposições de eleição de fontes definida por Gans (1979).

Se estes novos modelos de produção, onde o jornalista assume funções de recolha e tratamento de declarações de fontes acessíveis e de outros produtos noticiosos, poderiam sugerir o incremento do seu estatuto de gatekeeper (Millison, 1999), isto é, o seu exercício de vigilância, coleção e, sobretudo, seleção da informação, tal como preconizados por Shoemaker e Vos (2009), contudo, e resultante do que já se abordou serem os constrangimentos que o jornalismo contemporâneo enfrenta, o contexto da comunicação debate-se crescentemente com uma lógica inversa. Esta premissa não implica o completo definhamento da teoria (Canavilhas \& Rodrigues, 2012), antes se debate com as limitações intrínsecas descritas por McQuail (Apud Bastos, 2000). Ou seja, os constrangimentos gerados por uma nova realidade em que a informação chega às redações formatada para uma publicação imediata, adequada às rotinas de produção, como exemplo. Uma realidade onde a proliferação de canais se desenvolve numa relação exponencial comparável à profusão de informação (Chin-Fook \& Simmonds, 2011). E, a acrescer a tudo isto, uma realidade em que os jornalistas se veem obrigados a competir diretamente com novos modelos de comunicação, como os serviços online de demand media (Ramonet, 2011), as experiências de jornalismo participativo (Canavilhas \& Rodrigues, 2012) ou o "jornalismo cidadão" (Gillmor, 2005).

Como refere Jim Hall, os profissionais da comunicação adotam hoje novas funções, como o cartógrafo, que mapeia e encontra percursos na vastidão da internet. John Herbert resume a ideia: o jornalista perde a sua missão intrínseca de procurar e descobrir informação, limita-se agora a repescar no amplo espetro de 
informação disponível aquela que considera mais importante (Apud Aroso, 2001).

Todas estas novas tendências aqui analisadas representam um perigo óbvio para a qualidade da informação. Se, por um lado, resultam na anulação das diferentes abordagens das temáticas de discussão pública e na estandardização dos conteúdos e reprodução dos produtos informativos, fontes e ideologias (Correia, 2006), mais alarmante verifica-se a evidência de que resultam numa informação comprometida, em que práticas conduzem a uma atitude cuja preocupação com os pressupostos morais são relegados para um segundo plano, relativamente à necessidade de garantir prontamente o produto noticioso (Christians et al., 1998).

\section{Estudos anteriores}

Existe, até mesmo em Portugal, uma profusão de estudos exploratórios no âmbito da temática das fontes de informação e da relação que os jornalistas desenvolvem com estas (Sousa, 2002), cuja grande maioria denota tendências de incremento de uso de fontes anónimas, resultado, sobretudo, das condições de produção da notícia. Conquanto persista esta proliferação de análises, pelo objeto de estudo desenvolvido e pela relação intrínseca que desenvolvem com a presente investigação, destacar-se-ão três estudos.

A primeira análise, de Ana Rita Rocha (Apud Sousa, 2002), prende-se com o recurso a comentários de fontes anónimas nas peças políticas do jornal 'Expresso'. Numa amostra de 52 jornais (1998-1999), a autora encontrou 29 notícias onde figuravam este tipo de fontes. Constituindo-se maioritariamente peças não assinadas, estes artigos relacionavam-se sobretudo com questões de crítica política e desarmonia relacional. 
Mais aprofundadamente, os resultados do estudo de Ricardo Jorge Pinto (1997) à evolução do jornalismo político desenvolvido pelos diários 'The Times', 'The New York Times', 'Le Monde' e 'Diário de Notícias', entre 1970 e 1995, demonstra como já na década de 90 se evidenciavam as tendências discutidas anteriormente. Entre as principais conclusões, destaca-se a substituição de um modelo de jornalismo político baseado na descrição assente em longas citações diretas, para se assumir uma estrutura mais condicente com o modelo de análise dos acontecimentos. Assim, decresce o recurso a citações diretas.

Uma segunda conclusão prende-se com um decrescimento da utilização de fontes identificadas e, ao mesmo tempo, um aumento exponencial do recurso a fontes anónimas (Pinto, 1997), chegando em alguns jornais a ocupar um quarto dos casos retratados nas áreas destinadas à política. Se, em primeira análise, o autor atribui este fenómeno à necessidade implícita que o jornalista assume de gerar uma relação de proximidade com a sua fonte - aqui, obviamente, reportando ao jornalista especializado, como desenvolvido por Gans (1979) -, casos há, descritos por Pinto, em que a não referência à identificação da fonte depende de informações sobre as quais existe conhecimento mas não citação.

Ricardo Jorge Pinto (1997) infere também uma crescente diversificação de fontes, cuja razão o autor atribui ao desenvolvimento tecnológico e à evolução dos canais de comunicação.

Finalmente, a análise de Jorge Pedro Sousa (2002) às hard news de política dos jornais 'Diário de Notícias' e 'Público' no ano de 2001 conclui um diminuto recurso a fontes anónimas. $\mathrm{O}$ autor aponta diferentes explicações para o facto: uma tentativa de credibilizar o discurso jornalístico, dificuldade em desenvolver um jornalismo investigativo e de profundidade e a cedência às rotinas e à pressão do tempo. Uma outra explicação poderá residir no facto de, no ciberespaço, existir uma identificação dos recetores/ produtores de informação. 


\section{Metodologia}

No sentido de aprofundar e desenvolver o nosso objeto de estudo, optou-se por recorrer nesta investigação a uma abordagem metodológica assente na análise de conteúdo de diversos artigos publicados nas secções de política - ou nas editorias onde a temática é usualmente relevada. A análise de conteúdo consiste num "conjunto de técnicas de análise de comunicações visando obter, por procedimentos sistemáticos e objetivos de descrição de conteúdo das mensagens, indicadores (quantitativos ou não) que permitam a inferência de conhecimentos relativos às condições de produção/ receção (...) destas mensagens" (Bardin, 1979: 42). A par desta ilustração, como demonstra Mayring (2000: 3), esta técnica oferece a capacidade metodológica de colocar as questões da investigação em "categorias, as quais são cuidadosamente fundamentadas e revistas à luz do processo de análise".

Embora um fenómeno recente, verifica-se hoje claro o papel que as redes sociais - com predominância no Facebook - assumiram no desenvolvimento estrutural da comunicação e interação que originaria o protesto social português "Geração à Rasca"3 e que manteria a dinamização do movimento de contestação durante os diferentes momentos de protesto que se lhe seguiram (Loureiro, 2012; Evangelista, 2012; Fonseca, 2012). Desta forma, compreendeu-se que os momentos de contestação informal resultantes do protesto de 2011, pela profusão de intervenientes que oferece e pela articulação com diferentes canais de comunicação, constituem um objeto de estudo relevante para esta análise. Ao mesmo tempo, considerou-se que as manifestações organizadas pela central sindical CGTP-IN poderiam servir também como objeto comparativo.

3 Protesto convocado através das redes sociais que juntou milhares de pessoas no dia 12 de março de 2011. 
Assim, foram selecionados para o âmbito deste estudo todos os artigos - de género informativo (Martínez-Albertos, 1992) ${ }^{4}$ - diretamente relacionados com a temática dos protestos "Indignados" (15 de outubro), "Que se lixe a Troika: Queremos as nossas vidas!" (15 de setembro de 2012), "Que se lixe a Troika: O povo é quem mais ordena" (2 de março de 2013), bem como as manifestações nacionais promovidas pela CGTP-IN, (19 de setembro de 2012 e 16 de fevereiro de 2013), publicados nos cinco dias precedentes e decorrentes das ações. Tomou-se, portanto, como objeto de estudo os artigos publicados nas edições impressas dos diários portugueses 'Público' (57 artigos), 'Correio da Manhã' (55 artigos) e 'Diário de Notícias' (70 artigos). O objetivo da escolha destas publicações não passa por uma comparação em si, antes debate-se com a necessidade de compreender periódicos de diferentes grupos editoriais.

A análise dividir-se-á em diferentes variáveis relacionadas com o objeto de estudo. As duas primeiras variáveis consideradas prendem-se, obviamente, com a publicação e o evento a que o artigo se refere.

Tomando o quadro de Gargurevich (1982), a terceira variável refere-se à tipologia de artigo apresentado, sendo dividido entre breve, notícia, reportagem ou entrevista5.

Importância demonstrada no estudo de Rocha (Apud Sousa, 2002), também a questão da autoria é relevada nesta análise, através de uma divisão entre os artigos assinados por jornalistas, as peças cuja autoria é conferida a agência noticiosas ou os textos sem identificação de autor.

\footnotetext{
${ }^{4}$ Torna-se interessante, no entanto, verificar a capacidade da temática de estudo se estender longitudinalmente no tempo e espaço na área de opinião, relativamente ao espaço de informação.

5 Importa aqui referir que quatro vox pop, pelas características apresentadas, foram incluídos no género entrevista e que foram excluídas da análise fotolegendas e fotorreportagens, embora dois casos apresentassem material retirado exclusivamente da rede social Facebook.
} 
Retomando a discussão de Ericsson e Chan (1989) pretendeu-se catalogar a tipologia de fontes de informação - portanto de citação direta ou não - em oito categorias distintas: membros da organização dos protestos "Indignados" e "Que se Lixe a Troika", dirigentes sindicais, políticos da área governamental, políticos da área da maioria parlamentar, políticos da área da oposição parlamentar, manifestantes, polícia, jornalistas.

Finalmente, mais premente para a nossa análise, a sexta variável analisada debate-se com o modelo de contato com as fontes, onde foram entendidos os seguintes valores: contato direto, agência noticiosa, redes sociais, comunicado de imprensa.

No decorrer desta investigação e à medida que se tomava conhecimento da realidade da relação entre jornalistas e fontes, entendeu-se para uma compreensão mais ampla do fenómeno ser fulcral estender o objeto de estudo a uma nova análise. Foi, assim, incluída uma nova pesquisa relacionada com os dois momentos de contestação na residência oficial do Presidente da República, Palácio de Belém, dinamizados pela organização "Que se Lixe a Troika!" e pela CGTP-IN (20 e 25 de maio de 2013, respetivamente). Foram tomados como objeto de estudo todos os artigos publicados (16 artigos) sobre as temáticas nas edições impressas dos jornais portugueses 'Público', 'Diário de Notícias' ('DN'), 'Jornal de Notícias' ('JN') e 'Correio da Manhã' ('CM') ${ }^{6}$, nos dez dias anteriores e posteriores ao acontecimento.

Conforme o que já se verificou serem pressupostos alternativos do jornalismo digital, esta segunda parte de análise estendeu-se também aos artigos (53 peças) publicados nos sítios online dos jornais portugueses 'Público', 'DN', 'JN', 'CM', 'Expresso', 'Sol' e ' $I$ '. Nesta fase da pesquisa foram tomadas as mesmas variáveis

\footnotetext{
${ }^{6}$ Foram aqui excluídos os jornais 'Expresso', 'Sol' e 'I', por não possuírem nenhuma referência a estes acontecimentos nas suas versões impressas.
} 
de análise da primeira parte - excluindo no caso do online o género informativo.

\section{Análise e discussão dos resultados}

Relativamente à primeira parte da análise, referente às manifestações nacionais, como já ficou explícito, dos 182 artigos analisados, 57 artigos (31,3\%) constam no jornal 'Público', 55 (30,2\%) no ' $\mathrm{CM}$ ' e 70 artigos $(38,5 \%)$ no 'DN'. Estes artigos distribuem-se entre 79 breves (15,2\% no 'Público', 44,3\% no 'CM' e 40,5\% no 'DN'), 59 notícias (47,4\% no 'Público', 12,3\% no 'CM' e 40,4\% no 'DN'), 32 reportagens ( $43,8 \%$ no 'Público', $25 \%$ no 'CM' e '31,2\%' no 'DN') e 14 entrevistas (28,6\% no 'Público', 35,7\% no 'CM' e 35,7\% no 'DN').

Sobre os eventos tratados, 57 artigos (31,3\%) referem-se à manifestação "Indignados", 27 (14,8\%) à manifestação "Que se Lixe a Troika!: O Povo é Quem Mais Ordena”, 67 (36,8\%) à manifestação "Que se Lixe a Troika!: Queremos as Nossas Vidas", $12(6,6 \%)$ à primeira manifestação da CGTP-IN e $19(10,4 \%)$ à segunda manifestação da central sindical. Embora seja possível encontrar acontecimentos exteriores que possam relevar outras ocorrências relativamente às temáticas aqui desenvolvidas - a título de exemplo: a discussão sobre a TSU, jogos da seleção nacional ou a eleição do novo Papa - os eventos demonstram diferentes níveis de presença nos jornais. Este facto pode, obviamente, ser explicado pela novidade e proximidade que as manifestações representam - isto é, a conjugação de valores-notícia como a amplitude ou o significado (Galtung \& Ruge, 1965) com a novidade da situação (Stieler apud Kunczik, 2001). Ao mesmo tempo pode também ser explicado pela hipótese já aqui verificada de um maior grau de profusão e discussão online em torno deste tipo de ações, quando comparado com as iniciativas dinamizadas pela 
CGTP-IN - hipótese comprovada pela correlação com a tipologia de fontes e de contacto.

Relativamente às fontes, são os manifestantes que dominam o espetro do comentário citado, com 37,5\% dos casos, seguem-se os membros da organização "Que se Lixe a Troika!", com 15,9\%, e os políticos da área da oposição parlamentar, com 7,1\%. Dirigentes sindicais e polícia ocupam o mesmo espaço - 6,6\%-, reservando $2,7 \%$ dos casos para comentários por parte de políticos da área do governo e $2,2 \%$ para políticos da área da maioria parlamentar, 3,3\% das notícias são ocupadas com outro tipo de fontes. Já, 6,6\% das peças dependem unicamente da perspetiva do jornalista ${ }^{7}$. Em 13,2\% dos artigos a fonte não é identificável. Se estes dados validam a tese de Ricardo Pinto (1997), de um crescimento da diversidade de fontes - notável sobretudo no espaço que os manifestantes ocupam -, comprova também a ideia da existência de uma margem relevante do recurso a fontes não identificadas. É, no entanto, possível constatar que é entre a tipologia de breves que a não identificação das fontes mais acontece $(91,7 \%$ dos casos são breves), o que corrobora os dados e as hipóteses de Sousa (2002).

Sobre o tipo de contacto com as fontes, é o contacto direto que prevalece com $42,3 \%$ dos casos, seguindo-se as redes sociais $13,1 \%$-, o contacto através de conferência de imprensa, com 5,5\% dos casos e o comunicado de imprensa é referido como única fonte apenas em 3,8\% dos artigos. A citação através de agência noticiosa só aparece em 1,1\% das peças. Em 34,1\% dos casos, não existe uma referência direta ou indireta ao tipo de contacto realizado com a fonte. Mais uma vez, a não referência ao tipo de contacto assume uma margem relevante, sobretudo, quando correlacionada com outro tipo de variáveis. Verifica-se, assim, pertinente observar que a não identificação do tipo de contacto assume uma larga escala numa

7 Trata-se aqui de reportagens de ambiente. 
das publicações analisadas (65,5\% dos artigos do 'CM'), e natural perceber que ocorre sobretudo na tipologia de breves $(80,6 \%$ dos casos são breves) e que ocorre sobretudo nas peças não assinadas (em $91,9 \%$ dos casos o autor não é identificado).

Já no que concerne à utilização das redes sociais como fonte de contacto ocorre apenas uma vez no que concerne a peças sobre iniciativas da CGTP-IN. Assume maior relevância nas notícias (50\% dos casos ocorrem neste género) e desenvolve-se sobretudo com fontes como os membros da organização "Que se Lixe a Troika!" ( $50 \%$ dos casos) e os manifestantes ( $41,7 \%$ dos casos). Esta perspetiva corrobora, assim, a hipótese já avançada da novidade que este canal de comunicação representa, contraria contudo a tese de Ricardo Jorge Pinto (1997), quando se verifica que os manifestantes identificados através de redes sociais correspondem na sua totalidade a personalidades e pessoas de elite (Galtung \& Ruge, 1965).

Finalmente, relativamente ao autor das peças, 59,9\% são assinadas por jornalistas, 39,6\% não possui referência ao autor e apenas em $0,5 \%$ dos casos ( 1 artigo) a autoria é atribuída a agência noticiosa. Ainda que o valor de peças assinadas se assuma como maioria, constata-se uma margem relevante de peças não assinadas. Este dado, hipoteticamente, poderá vincar quatro conclusões: tratar-se de textos de agência noticiosa, a sua dependência de fontes não identificadas ou de acesso não direto implicar a opção editorial de não assinar o artigo, a sua inclusão em secções dedicadas à temática presumir a autoria de artigos circundantes assinados ou o facto de se referirem a breves (em 32,4\% do total dos casos existe um cruzamento das duas variáveis) acarretar a escolha editorial de não referir a autoria.

No que concerne à segunda parte da análise, relativa às concentrações no Palácio de Belém, verifica-se que dos 16 artigos publicados em versão impressa $6(37,5 \%)$ se referem à concentração promovida pela organização "Que se Lixe a Troika!", enquanto 10 $(62,5 \%)$ se referem à concentração promovida pela CGTP-IN. Nos 
artigos online, do total de 53 artigos, 22 (41,5\%) abordam a primeira concentração e $31(58,5 \%)$ se debruçam sobre a segunda ação.

Sobre a disposição de artigos por órgão de comunicação impresso, 'JN' e 'DN' possuem cada um 6 artigos (37,5\%), e 'Público' e 'CM' possuem cada um 2 artigos (12,5\%). No online esta dispersão é maior, constando 12 artigos (22,6\%) no sítio 'Público.pt', 12 (22,6\%) no sítio 'JN.pt', 9 (17\%) no sítio 'DN.pt', 6 (11,3\%) no sítio 'IOnline', 5 (9,4\%) no sítio 'Expresso.pt', 5 (9,4\%) no sítio online jornal 'Sol' e $4(7,5 \%)$ no sítio online do jornal 'Correio da Manhã'. Importa, contudo, referir que em três casos o mesmo artigo se repete na versão impressa e no formato online do jornal.

No que respeita à tipologia de artigos impressos, estes distribuem-se entre 11 breves (68,8\%), quatro reportagens (25\%) e uma notícia (6,3\%).

A questão da autoria conhece uma lógica semelhante à da primeira parte desta análise. Do total de artigos impressos, 37,5\% são assinados por jornalistas e $62,5 \%$ não possui autoria. Mais uma vez é entre as breves que a não atribuição da autoria ocorre (todos os artigos não assinados são breves). Já no online, o paradigma é completamente inverso: $32,1 \%$ dos artigos são assinados por jornalistas, $1,9 \%$ não possui autor e em $66 \%$ dos casos a autoria é atribuída a agência noticiosa. Este último dado poderá corroborar a primeira hipótese formulada para a questão da autoria, desenvolvida na primeira parte da análise.

Novamente, a questão das fontes conhece realidades distintas entre o formato impresso e o online. No primeiro caso são os manifestantes que dominam o espaço do comentário, com 18,8\% dos casos, seguem-se os dirigentes sindicais com $12,5 \%$ e os membros da "Que se Lixe a Troika!" e políticos da área da oposição parlamentar, com 6,3\% dos casos cada um. No entanto, em 56,3\% dos casos, a fonte não é referida. No online, o espaço dos manifestantes rivaliza com o dos dirigentes sindicais e o dos políticos da área da oposição (20,8\% cada um), seguindo-se os elementos da organização "Que se Lixe a Troika!”, com 15,1\% dos casos e os políticos da área gover- 
namental, com 3,8\%. Em 18,9\% das peças, a informação depende da perspetiva do jornalista. Mais uma vez, verifica-se - no caso do formato impresso - que é entre as breves que a não identificação da fonte de informação ocorre com maior preponderância (todas as peças em que não existe referência à fonte são breves) e que é entre os artigos sem autoria ( $80 \%$ dos casos) que esta prática prevalece.

Relativamente ao método de contacto com as fontes, nos artigos impressos denota-se uma divisão entre o acesso direto à fonte (31,3\%) e uma combinação do recurso ao contacto direto e a utilização de informações de agência noticiosa (68,7\%). A dispersão é maior no formato online, onde o contacto direto continua a dominar $(73,6 \%)$, mas se verifica também a aproveitação da informação disponível das redes sociais (11,3\%), a utilização de informações de agência noticiosa $(3,8 \%)$ e o recurso marginal a comunicados de imprensa como única fonte (1,9\%). Em 9,4\% dos artigos não existe referência ao método de contacto com as fontes. Ainda que não se constitua um dado essencial para esta análise, interessa conferir que o contacto direto se desenvolve maioritariamente nos artigos assinados por agência noticiosa (71,8\%), assim como o contacto através de redes sociais (66,7\%). Já a não identificação da forma de contato ocorre sobretudo nos artigos assinados por jornalistas (60\%). Enquanto o contacto através das redes sociais se estabelece integralmente para a citação de membros da organização "Que se Lixe a Troika!", o acesso direto às fontes ocorre sobretudo entre fontes oficiais (Sigal, 1970), como os dirigentes sindicais e os políticos da área da oposição parlamentar (23,1\% cada um).

\section{Conclusões}

A mutação das rotinas produtivas do jornalismo e o desenvolvimento tecnológico das redações vieram transformar o modelo de relação entre jornalistas e fontes. As fontes estão hoje muito mais acessíveis, 
através de novos canais de comunicação, onde prolifera a informação e discussão. Se esta nova ideologia se enquadra mais convenientemente na lógica socioeconómica contemporânea do jornalismo, ao mesmo tempo deixa adivinhar uma perda da qualidade do produto noticioso, enquanto se figura também alarmante no que respeita ao cumprimento dos preceitos éticos e deontológicos inerentes ao jornalismo. Resulta isto de um menor contacto com as fontes e o acontecimento, de um declínio do gatekeeping ou da burocratização crescente do ofício.

A análise aos dados obtidos, conquanto prossegue as conclusões de estudos anteriores, demonstra resultados preocupantes. Resultados que se vertem numa margem desenvolvida de fórmulas de contacto com o acontecimento, que não a do acesso direto. $\mathrm{E}$ onde se destacam também a margem relevante do contacto através das redes sociais ou a não identificação do modelo.

Denota-se ainda, como já tinha encontrado Ricardo Jorge Pinto (1997), uma tendência crescente de recurso a tipologias de fontes não oficiais, sem que se confirme uma democratização do acesso ao discurso citado, ou seja, prossegue-se a tese desenvolvida por Gans (1965) de uma dominação das fontes conhecidas, mesmo nestes novos canais. Tipologia de comunicação onde se verifica uma permanência das lógicas inerentes aos valores da notícia.

Por fim, fica patente uma alteração das normas e rotinas produtivas, e da organização redatorial, expressa no número de artigos sem assinatura, no número de artigos conferidos a agência noticiosa - no online - e, hipoteticamente, nas tipologias de artigo preteridas nos modelos impressos.

\section{Referências bibliográficas}

Antunes, S. (2002, agosto 19). Os políticos mais populares do Facebook. TVI24. Disponível em: http://www.tvi24.iol.pt/tecnologia/facebook-louca-cavaco-passos-portas-tvi24/1369033-4069.html. 
Aroso, I. (2001). A internet e o novo papel do jornalista. Biblioteca Online de Ciências da Comunicação, Universidade Beira Interior. Disponível em: http://bocc.ubi. $\mathrm{pt} / \mathrm{pag} /$ aroso-ines-internet-jornalista.pdf.

Bardin, L. (1979). Análise de Conteúdo. Lisboa: Edições 70.

Bastos, H. (2000). Jornalismo Electrónico: Internet e reconfigurações de práticas nas redacções. Lisboa: Minerva.

Bastos, H. (2002). A viragem digital do jornalismo. In J. Miranda \& J. Silveira (Ed.), As Ciências da Comunicação na Viragem do Século. Lisboa: Vega.

Blumler, J., \& Gurevitch, M.1 (2005). The Crisis of Public Communication. Londres: Routledge.

Canavilhas, J. (2009). Calidad de la informacionón periodística en Internet. In J. Vivar \& F. Ramírez. Periodismo 2.0. (pp. 31-40). Madrid: Editorial Fragua

Canavilhas, J. (2010). Do gatekeeping ao gatewatcher: o papel das redes sociais no ecossistema mediático. In II Congresso Internacional Comunicación 3.0, Salamanca.

Canavilhas, J.; Rodrigues, C. (2012). O cidadão como produtor de informação: estudo de caso na imprensa online portuguesa. OBS -Obercom. 9 (2), 269-283.

Castells, M. (2009). Comunicación y Poder. Madrid: Alianza Editorial.

Chaparro, M. (2001). Linguagem dos Conflitos. Coimbra: MinervaCoimbra.

Chin-Fook, L. \& Simmonds, H. (2011). Redefining Gatekeeping Theory For A Digital Generation. The McMaster Journal of Communication. 8 (2).

Christians, C. (Org.) (1998). Media Ethics: Cases and Moral Reasoning. Nova Iorque: Longman.

Curran, J. (1996). Rethinking Mass Communication. In J. Curran, D. Morley \& V. Walkerdine (Eds.), Cultural Studies and Communication. Londres: Arnold.

Dean, J. (2009). The Promises of Communicative Capitalism. In J. Dean (Ed.), Democracy and Other Neoliberal Fantasies: Communicative capitalism and left politics. Duhram: Afrontamento.

Ericsson, R., Baranek, P. \& Chan, J. (1989). Negotiating Control: A study of news sources. Toronto: University Press.

Evangelista, R. (2011). Revoluções a La Web. Ciência e Cultura. 63 (2), 18-21.

Fonseca, D. (2012). A mobilização de 12 de março em Portugal: movimento social ou "explosão"? Atores, processos e consequências. Sociologia, Revista da Faculdade de Letras da Universidade do Porto. 24, 113-131.

Galtung, J. \& Ruge, M. (1965). The Structure of Foreign News. Journal of Peace Research. 2 (1), 64-91.

GANS, Herbert (1979). Deciding What's News: A study of CBS Evening News, NBC Nightly News, Newsweek, and Time. Illinois: Northwestern University Press.

Gargurevich, J. (1982). Géneros Periodísticos. Quito: Editorial.

Gillmor, D. (2005). Nós os Media. Lisboa: Editorial Presença.

Gomes, R. M. (2009). A Importância da Internet para Jornalistas e Fontes. Lisboa: Livros Horizonte.

Hall, S. (1999). Policing the Crisis. In H. Tumber (Ed.), News Reader. Oxford: Oxford University Press. 
Hess, S. (1984). The Government/Press Connection: Press officers and their offices. Washington: The Brookings Institution.

Kovach, B. \& Rosenstiel, T. (2001). Elementos do Jornalismo: o que os profissionais do jornalismo devem saber e o público deve exigir. Porto: Porto Editora.

Kunczick, M. (2001). Conceitos de Jornalismo: Norte e sul. São Paulo: Editora da Universidade de São Paulo.

Loureiro, L. (2012). O ecrã da identificação. (Tese de Doutoramento em Ciências da Comunicação). Braga: Universidade do Minho.

Machado, E. (2002). O ciberespaço como fonte para os jornalistas. Biblioteca Online de Ciências da Comunicação, Universidade Beira Interior. Disponível em http:// bocc.ubi.pt/pag/marques-ester-contradicoes-liberdades.html.

Martínez-Albertos, J. L. (1992). Curso General de Redacción Periodística: Lenguaje, estilos y géneros periodísticos en prensa, radio, televisión y cine. Madrid: Paraninfo.

Mayring, P. (2000). Qualitative Content Analysis. Forum: Qualitative Sozialforschung. $1(2)$.

McQuail, D. (2003). Teoria da Comunicação de Massas. Lisboa: Fundação Calouste Gulbenkian.

Meireles, S. G. (2007). Os Jornalistas Portugueses: Dos Problemas de Inserção aos Novos Dilemas Profissionais. Coimbra: MinervaCoimbra.

Millison, D. (2009). The Journalist of Tomorrow. American Press Association. Disponivel em: http://www.americanpressassociation.com/journalist_of_tomorrow.php.

Miranda, J. (2012). Os efeitos do novo paradigma socioprofissional do jornalismo sobre as práticas de ética e deontologia. (Tese de Mestrado em Comunicação e Jornalismo). Coimbra: Universidade de Coimbra.

Mitchell, A.; Rosenstiel, T. (2012). What Facebook and Twitter Mean for News. The State of the News Media. Disponível em: http://stateofthemedia.org/2012/ mobile-devices-and-news-consumption-some-good-signs-for-journalism/what-facebook-and-twitter-mean-for-news/.

Molotch, H.; Lester, M. (1974). News as purposive behavior. On the strategic use of routine events, accidents, and scandals. American Sociological Review. 39 (1), 118-137.

Neveu, E. (2001). Sociologie du Journalisme. Paris: La Découverte

Oriella PR Network (2011). Digital Journalism Study 2011. Oriella PR Network. Disponível em: http://www.orielladigitaljournalism.com/view-report.html.

Pavlik, J. (2005). El Periodismo y los NuevosMedios de Comunicación. Barcelona: Paidós.

Pereira, F. H. (2003). Jornalista On-Line: um novo status profissional?. 2003. (Tese de Mestrado em Comunicação). Porto Alegre: Universidade Federal do Rio Grande do Sul.

Pinto, R. J. (1997). The Evolution of Structure of Political Journalism in Four "Quality" Newspapers (1970-1995). (Tese de Doutoramento em Culture and Media Studies). Brighton e Hove: Universidade de Sussex.

Ramonet, I. (1999). A Tirania da Comunicação. Porto: Campo das Letras. 
Ramonet, I. (2011, março 11). Autômatos da informação. Le Monde Diplomatique Ed. Bras.. 4 de Março de 2011. Disponível em: http://diplomatique.uol.com.br/ artigo.php?id=904.

Recuero, R. (2009). Redes Sociais na Internet, Difusão de Informação e Jornalismo: Elementos para discussão. In D. A. Soster \& F. Firmino (Eds.), Metamorfoses Jornalísticas 2: A reconfiguração da forma. Santa Cruz do Sul: UNISC.

Roberts, M. \& McCombs, M. (1994). Agenda Setting and Political Advertising: Origins of the news agenda". Political Communication. 11 (3), 249-262.

Santos, R. (1997). A Negociação entre Jornalistas e Fontes. Coimbra: Minerva.

Schlesinger, P. (1999). Os jornalistas e a sua máquina do tempo. In N. Traquina (Ed.), Jornalismo; Questões, Teorias e "Estórias". Lisboa: Vega Editora.

Serrano, E. (1998). As Relações entre a Comunicação Institucional e o Jornalismo. In $3 .^{\circ}$ Congresso dos Jornalistas Portugueses, Lisboa.

Shoemaker, P. \& Vos, T. (2009). Gatekeeping Theory. Nova Iorque: Routledge.

Sigal, L. (1973). Reporters and Officials: The organization and politics of newsmaking. Lexington: D. C. Heath.

Sousa, J. P. (2000). As Notícias e os seus Efeitos: As "Teorias" do Jornalismo e dos Efeitos Sociais dos Media Jornalísticos. Coimbra: MinervaCoimbra.

Sousa, J. P. (2002). A utilização de fontes anónimas no noticiário político dos diários portugueses de referência: Um estudo exploratório. Biblioteca Online de Ciências da Comunicação, Universidade Beira Interior. Disponível em: http://www.bocc. ubi.pt/pag/sousa-jorge-pedro-utilizacao-fontes-anonimas.pdf .

Traquina, N. (1988). As notícias. Revista de Comunicação e Linguagens, Jornalismos. 8.

Tuchman, G. (1978). Making News: A study in the construction of reality. Nova Iorque: The Free Press.

Wolf, M. (2010). Teorias da Comunicação. Lisboa: Presença.

[Este trabalho é enquadrado pela Fundação para a Ciência e Tecnologia (FCT) através da bolsa de doutoramento FCT SFRH/BD/8702012012] 